\title{
The Influence of Political Messages on User Engagement within Social Media Environments
}

\author{
Ronda Mariani \\ Bloomsburg University \\ Fitzgerald L. Price \\ Saint Leo University \\ Janelle Gumbs \\ Saint Leo University
}

\begin{abstract}
This study explores the predictors of user interactions in response to political messaging within the social media environment. Research exposes whether trust had a significant role in social media user's engagement and identifies what factors determine user trust. Using a cross-sectional survey methodology, data was collected based on descriptive characteristics of survey respondents. Scales were also used to evaluate trust interpretations of political messages. Respondents overwhelmingly indicate that trust was a key consideration when engaging political messages on social media. Findings indicate a significant increase in the trust of political messages generated by Facebook and Twitter social media platforms.
\end{abstract}

\section{INTRODUCTION}

The importance of trust is critical to almost all we do. Whether it is selling a product, service, or a political message, trust always seems to play a role in consumer decision-making. Trust building among consumers and constituents has become a strategy for many organizations, including political, knowing trust creates value if it is established (Singhal, 2016). Additionally, the importance of trust is not limited to enticing users to engage with a specific online community but also contributes to convincing users to remain active participants (Potgieter \& Naidoo, 2017). Social media has introduced a new framework to understand social interactions and the user's favorability towards their social decisions (Stephen \& Toubia, 2010). Social interaction influences the intention to engage with others actively. This external motivation has often promoted long-term social engagement and sharing of experiences and opinions with like-minded people (Yichuan \& Chiahui, 2017).

However, Chen \& Wang (2017) argued that social engagement had very little to do with personal decision-making. The main predictors associated with making decisions were determined to be individual cognitive and affective appraisal measures (Sakakibara \& Endo, 2016). Understanding the role that trust contributes to the emotional responses of social media users can provide insight that "consumer trust is a key variable to a positive emotional response" (Hahn, Scherer, Basso, \& dos Santos, 2016, p. 49). 
Political messages have relied heavily on establishing trust among their constituents to develop support for their campaigning messages. If trust is established through emotional engagement, long-term relationships can be obtained with constituents (Towns, 2012) providing positive support and decisionmaking in regards to political messages. The establishment of a sustainable relationship based on trust can moderate constituent loyalty and garner commitment (Melewar, Foroudi, Gupta, Kitchen \& Foroudi, 2017).

Research regarding political messages and digital media usage began in late 1990 and later with exceptional usage by President Barack Obama's political campaign (Copeland \& Rommele, 2014). Political campaigns have historically been covered in the mass media with a focus on the leading candidates (Van Aelst, van Erkel, D'heer \& Harder, 2017). Today, throughout many countries, social media is increasingly used as a vehicle to promote political messages. Chan (2017) posited that social media organizations are essential suppliers of information that can be used to motivate and influence individual political engagement. Currently, political leaders such as President Trump and President Obama, Sheikh Mohammed, Speaker Boehner, Governor Kasich, and Indian Prime Minister Narendra Modi (Mann, 2014) tweet to keep their constituents informed. The use of Twitter is unique in that words, as opposed to pictures and other visual enhancements, which are found using Instagram or Pinterest, are the primary driver of user engagement.

There is a concerted effort by those whom Tweet to strike a balance between personal and public information, sidestep topics where there is no interest, and present themselves as authentic (Brems, Temmerman, Graham \& Broersma, 2017). Keeping the content exciting and communicating regularly also contributes to the number of followers a political campaign may have (Spierings \& Jacobs, 2013). Schill \& Hendricks (2018) described effective strategies employed by then Presidential candidate Donald J. Trump to keep followers engaged. Activities associated with these strategies included being personable, thanking supporters, inviting them to campaign events, and encouraging constituents to celebrate campaign successes. It has been assumed that the more followers you have, the more successful your political message will be; this may not be the case (Spierings \& Jacobs, 2013).

It has also been found that when using social media in campaigns requiring voting, the message conveyed was important to followers (Spierings \& Jacobs, 2013; Crawford, 2009; Wilson, 2009) and the emphasis on continued maintenance of these relationships proved significant (Grimmer, Messing, \& Westwood, 2012). The co-creation of value for users concerning social media performance and user personalization represented a useful framework for relationship marketing (Sheth, 2017). For this study, social media referred to Facebook and Twitter. This study further researched the impact of trust on the social media platforms; Facebook and Twitter, and determined if trust impacted the users' social media emotional response towards political messages that other users typed or tweeted.

\section{LITERATURE REVIEW}

Prior studies have identified the inclusive nature of social media in that it provided a voice to anyone who desired to participate regardless of background, financial capability, or political affiliation. The use of social media has contributed to the increase in interpersonal discussion about local and national politics providing users insight into the viewpoints of others. This awareness coupled with engagement has increased the user's level of political knowledge (Park, 2017). As a result of a study conducted by Ardevol-Abreu, Diehl \& Gil de Zuniga (2017), media consumption of news was a predictor of political interaction. Information with political overtones accessible from online media sources, whether from intentional downloading or accidental viewing, was determined to perpetuate political discussion (Weeks, Adrevol-Abreu \& Gil de Zuniga).

A survey conducted by Young (2017) indicated that the primary reason Human Service Organizations (HSO) used social media was the promotion or advertising of services or events $(96 \%, \mathrm{~N}=120)$ followed by community engagement $(92 \%, \mathrm{~N}=115)$. Additionally, Facebook $(98 \%)$ and Twitter $(72 \%)$ were considered the two most widely used social media platforms. McNair (2018) emphasized that comprehending the impact of media messages required an understanding of the elements of 
communication. The interpreting of messages from different groups required the incorporation of the elements of diversity, audience makeup, and the expectation of varying responses as critical components for evaluation. Meaning and response would be contingent upon message reception with the inclusion of such factors as political affiliation, age, ethnicity, the gender of the receiver, and the language in the message being transmitted, and how the individual interprets the language within that message.

Bode (2017) explored social media engagement by examining three broad categories that included social media for political purposes, reacting to disagreeable political content on social media, and offline reactions to political, social conduct. Results indicated that gender differences appeared to be less prevalent in relation to political engagement on social media. Furthermore, men were more likely to post political information on social media platforms such as Facebook and Twitter and women were slightly more likely to unfriend people on Facebook for political points of view.

A subset of interview data $(\mathrm{N}=42)$ from two distinct studies was extracted from the research efforts of Duffy, Pruchniewska \& Scolere (2017). The first study evaluated the digital self-presentation practices of female entrepreneurs. The second study examined how designers utilize social media to promote their professional profiles. An interview sample of 27 women and 15 men was taken from a diverse pool of people including designers, artists, professional bloggers, marketing consultants, publicists, entertainers, content producers, and small business owners.

Participants identified Facebook and Twitter as two of the social media platforms that they frequented. Interview results affirmed the importance of having a clear understanding of digital media use within a social system that thrived on connectedness. Furthermore, the researchers indicated that users who viewed social media as pivotal to their professional and personal self-promotion should have a fundamental understanding of its overarching social ecology. Moreover, trust has been reported to be a critical factor in an individual when deciding an individual's decision to engage in social media. A user's trust in their preferred social media platform translated into increased engagement (Hajli, Sims, Zadeh \& Richard, 2017).

\section{Trust in Information}

Trust has been broadly defined as an expectation people have with others, institutions, and organizations in the societies they live that serve as a fundamental basis for social and moral order (Himelboim, Lariscy, Tinkham, \& Sweetser, 2012). Previous studies revealed mixed results regarding Internet use and trust in the information received. Himelboim et al. (2012) supported previous research that people who already trust information from a variety of sources are also strong end users of various media spaces for acquiring political information. Although there was no consensus regarding the effects of the Internet, political engagement and trust, there was a sense of optimism regarding the ability of online political engagement used to increase conventional forms of political participation (Cho et al., 2009; Gil de Zúñiga, Jung, \& Valenzuela, 2012).

\section{Political Messages and Social Media}

Social media platforms such as Facebook and Twitter provide opportunities where individuals can exchange and share political opinions and information (Twitter and social networking in the 2010 midterm elections, 2011). Warren, Sulaiman, and Jaafar (2014) supported previous studies that showed Facebook was used by activists for social causes and the individual struggles were magnified by the click of a mouse. Because of this, global issues were accessible by anyone with access to the Internet.

\section{Political Party Affiliation and Social Media}

Previous research revealed that social media had become a robust facet of political and civic engagement for many Americans (Rainie, Smith, \& Schlozman, 2012). Studies have shown that participation in online political groups was intensely correlated with offline political engagement, which was associated with functions of political party members engaging online (Conroy, Feezell, \& Guerrero, 2012). 


\section{Gender and Social Media}

Studies regarding gender and social media use found that while outgoing and expressive men and women were both likely to be frequent users of social media sites (SMS), men with greater degrees of emotional instability were more regular users; however there was no significant relationship detected between men and women's emotional stability (Correa, Hinsley, \& Gil de Zúñiga, 2010). Anderson (2015) found that the overall percentage of men and women who reported using social media was comparable; there were gender differences in the use of specific social networking sites. Findings of recent research found that men used social networking sites to start new relationships, whereas, women used social networking sites to maintain existing relationships (Muscanell \& Guadagno, 2012).

\section{Generational Cohort and Social Media}

Leung (2013) posited that there were no generational differences when using Facebook or blogs to satisfy social and affection needs. However, Leung (2013) detected differences in social media usage among Baby Boomers born from 1946 to 1964 having varying narcissistic personalities. Prior research showed that millennials born 1977 to 1995 were two and a half more times more likely to be early users of technology than other generations and felt that their lives were more prosperous through connections to others through social media (Fromm \& Porter, 2016).

\section{RESEARCH PROBLEM}

As of 2018, the use of traditional forms of media to provide messages to constituents has not been as impactful as online social media environments, such as Facebook and Twitter. Research has found certain mediums such as television, no longer have supremacy in political communication (Tanase, 2015, p. 93). Tanase (2015) stated, "Facebook pages of candidates is not necessarily an area for debate but rather a source of message broadcasting among fans, it is here that the debate begins among friends, who are also known as online political citizens" (p. 93). We can agree that there is an importance to understanding this interaction between "online political citizens" (Tanase, 2015, p.93) and the development of trust between constituents and candidate's political messages. This interaction between online political citizens, the sense of trust, and a candidates political message have not been thoroughly explored. The digitizing of political campaigns has enabled candidates to obtain further reach, not only to their constituents but impressionable citizens as well (Gerodimos \& Justinussen, 2015). Therefore understanding the impact of trust on motivating engaging relationships between constituents and political messages may generate "higher conversion rates, which will lead to increased confidence vote" (Tanase, 2015).

\section{Basis of the Study}

This study was based on the research of several scholars. Singhal (2016) found that trust created value if it is established. Hahn, Scherer, Basso, and dos Santos (2016) found that consumer trust was a key variable to a positive emotional response. Ha (2004) found that trust was significant in building brand relationships. Hahn et al. (2016) found that brand trust was linked to an emotional response to advertisements. In the case of this study, advertisements would be political messages.

\section{Purpose of the Study}

The purpose of this study was to explore the predictors of user interaction in response to political messages within social media environments, such as Facebook and Twitter. This research examined the influence of constituent trust, political party affiliation, and negative/positive political messages on user engagement on a social media platform. In addition, the influence of the demographic variables of gender and generational cohort on social media user engagement in response to political messages was also explored. 


\section{Trust a Predictor of User Engagement}

Phillips (2017) reported on the decline of trust in mainstream media in America. This decline had been attributed to the presence of a robust commercial system. In the United States, media overall had garnered low levels of trust for both television news and the press in general. This sentiment is a direct result of traditional media systems that no longer had the wherewithal to command public respect. Furthermore, access to current events by way of social media has exasperated this situation. As social media platforms gain greater user participation, traditional purveyors of public information have had to do everything possible to maintain current subscribers and rebuild lost trust. This effort has required an exercise of courage requiring the dissection of public statements made by politicians and pundits and the pushing back when utterings prove to be exaggerations or inaccuracies.

Levy, Newman, Nielsen, and Fletcher (2016) explored in detail the role of public trust in the media. Focus groups were held in the countries of Germany, Spain, the United States, and the United Kingdom to understand more about the motivators for trusting or not trusting media sources. Based on geographic location, findings indicated varying views as to the level of media trust. Overall media trust in the U. S. (33\%) was found to be lower in comparison to other countries evaluated. Creators of social media content have recognized the need to provide high-quality experiences to attract and keep users continually engaged. Additionally, traditional mass media organizations have embraced social media platforms such as Facebook and Twitter and have become heavily invested in websites and online applications where loyal users can be cultivated. This effort has been undertaken to remain relevant as well as bolster sagging revenue (Levy, Newman, Nielsen, \& Fletcher, 2016). Given these findings, the following hypothesis was proposed:

H1: Trust is a significant predictor of user engagement in response to political messages posted within a social media environment.

\section{Negative Political Messages Have Positive Influence}

As of 2016, individual intake of political news has more commonly been experienced because of engagement with social media platforms. Users absorb information, react, and share their impressions with others instantaneously. Media organizations such as CNN, MSNBC, Fox News, Al Jazeera Media Network, National Public Radio, and many more monitor usage algorithms and develop content based on this activity (Wells et al., 2016). As a result, social media users are provided the means to develop and send messages across social networks perpetuating online communities (Neubaum \& Krämer, 2017). Bhattacharya (2016) has suggested that efforts to categorized negative campaign communications strategies into identifiable topics may be ill-considered. Depending on the intentions and motivations of political candidates, negative campaign messages may or may not solicit voter support. Research findings have indicated that prospective voters could obtain as much or as little political messages as desired. This potential for discretionary message selection may account for increased political partisanship and voter choices when engaging with specific media sources, such as Facebook and Twitter. A strategist with the capability to capitalize on how different levels of media exposure may affect voting patterns will be able to manage more effectively their candidate's campaign.

As voters increasingly seek political messages that support their viewpoint, campaigns have used these opportunities to focus attention on those who oppose their messages with negative attention. Brader (2006) indicated that targeting approaches may include the suppression of voter turnout or appeal to them on cross-cutting issues. Hillygus and Shields (2009) indicated that polarization might be a contributing factor to the increase in negative ads. Most of these approaches have resulted in increased partisan engagement as opposed to efforts to cultivate support from those with opposing political views. Republicans have been observed to screen opposing content more vigorously than Democrats. However, both Democratic and Republican political candidates have relied on screening results to address these findings, but implement tactics differently when concerning message targeting (Henderson, \& Theodoridis, 2015). Based on the discussion, the following hypothesis was proposed: 
H2: Negative political messages have a positive influence on social media user's engagement within a social media environment.

\section{Positive Political Messages have a Positive Influence}

Positive campaigns are typically described as strategic approaches or political situations where a candidate, campaign, or party has decided to focus primarily on the promotion of their respective policies, agendas, voting records, characteristics, and experiences (Carraro et al., 2013; Sullivan and Sapir, 2012: 294). Positive campaigns have been further described as occasions where candidates or parties have presented evaluations of a political rival's policy stands, qualifications, or other non-rhetorical information (Stevens et al., 2008). Roy \& Acantara (2016) explored the impact of campaign tone in conjunction with the engagement of negative messaging to garner increased voter attention. Results indicated that a rise in candidate attention was not affected by other candidates participating in negative campaigning. Even though candidates received increased attention, more attention did not result in increased voter rates. Finally, results indicated that voters in a multiparty setting are not motivated by negative messages as it related to the selection of a political candidate. Because of these findings, the following hypothesis was proposed:

H3: Positive political messages have a positive influence on social media user's engagement within a social media environment.

\section{Political Party Affiliation is a Predictor of User Engagement}

The use of social media platforms has been reported to account for approximately 30 percent of the time Americans spend online (Mander, 2015). Despite user contention that SMS address specific social purposes, political message content on SMS has become commonplace (Rainie \& Smith, 2012; Vraga et al., 2015). Mitchell \& Weisel (2014) reported that 48 percent of Facebook users obtain local news, national news, government and political information from Facebook. Furthermore, 75 percent of users indicated that friends on SMS had posted content during the 2012 election (Rainie \& Smith, 2012). SMS has also been credited with providing timely exposure to political content as well as representing a more diverse environment than offline political engagement (Rainie \& Smith, 2012). User exposure to incongruent political content has not translated into more online engagement although it may have increased the risk of posting political ads when facing an unknown or hostile audience (Eveland \& Hively, 2009; Marwick \& Boyd, 2010; Vraga et al., 2015). Furthermore, exposure to congruent and incongruent political information on SMS has suggested that message filtering activities may be occurring (Colleoni et al., 2014). Political scholars have been concerned with such filtering positing that unintentional exposure to political messaging may result in increased levels of incongruent political content. Social media has been touted for the potential to serve as a conduit into optional forms of participation (Bode, 2017) but if it also functions more effectively for one group (Republicans) than another (Democrats). This imbalance may create inequalities in involvement between these groups. Given these findings, the following hypothesis was proposed:

H4: Political party affiliation is a significant predictor of user engagement in response to political messages posted within a social media environment.

\section{Gender is a Predictor of User Engagement}

A study conducted by Fridkin and Kenney (2011) found that women were significantly less tolerant of negative campaign messages when compared to men. Findings were obtained from the fields of evolutionary psychology, communication, and political science indicating that women are more likely than men to avoid negative stimuli. Women were also to be less tolerant of negative news and negative campaigning. Men and women had different responses to fact-check messages assessing negative advertisements. It was concluded that fact-check messages confirming the inaccuracy of a negative 
advertisement would have more influence on women than men (Fridkin, Courey, Hernandez \& Spears, 2016). Given these findings, the following hypothesis was proposed:

H5: Gender is a significant predictor of user engagement in response to political messages posted within a social media environment.

\section{Generational Cohort is a Predictor of User Engagement}

The decline in support for democracy has not only been a story of the young being more critical than the old but rather an outcome attributed to the cohort as opposed to age. The health of a democracy is reliant on a commitment to critical political values which include civil rights as well as the active engagement of an informed public. It has been reported that, since the 1960s, voter turnout has decreased along with political-party membership (Foa \& Mounk, 2016). Social media usage has appeared to be the way of reenergizing the public. Moreover, research findings have determined that social media platforms that support online transactions enhance the purchase of goods and services. Being aware of the frequency levels of social media usage for all cohorts, allow for more effective target marketing. This level of awareness coupled with the increase of relationship strength has resulted in a long-term impact on business relations as well as garnering increased customer support (Fietkiewicz, Lin, Baran \& Stock, 2016). Based on this discussion, the following hypothesis was proposed:

H6: Generational cohort is a significant predictor of user engagement in response to political messages posted within a social media environment.

\section{RESEARCH QUESTION}

Political message managers would benefit by understanding how trust impacts social media user's emotions toward their political messages posted on social media platforms. Political messages are similar to brand advertisements, and past research has demonstrated that trust is significant in building brand relationships (Ha, 2004). The same can be applied to political messages. The research problem in this study focused on the user's motivation to engage with political messages and if trust played a significant role in this engagement. Engagement and the degree of engagement were identified by whether or not the social media user responded to a political message. This interaction was in the form of a tweet or the use of social buttons, such as like, share, and/or comment. Two major social media platforms were researched, Facebook and Twitter. The research question explored was the following:

RQ1: What motivates social media users to engage with political messages posted within a social media environment such as Facebook or Twitter?

Dependent Variables

- Engagement

○ Motivation

Independent Variables

- Trust

- Approval (of social media use for political messages)

- Political party affiliation

- Message type (positive vs. negative)

- Gender

- Generational cohort 


\section{Population Sample}

The target population for this study consisted of social media users, specifically Facebook and Twitter. A convenience sampling method was used to reach the most significant number of participants. To participate in the study, participants had to meet the following criteria; be at least 18 years of age or older and be active social media users, specifically Facebook and Twitter.

\section{Definition of Terms}

The following terms are found throughout this study.

- Engagement represents the use of Twitter and social buttons (like, comment, and share) (Gerodimos \& Justinussen, 2015).

- Political messages are social media posts that provide constituents with governmental information, communication, and participation channels in which constituents can engage with politicians and their messages (Song \& Lee, 2015).

\section{Overview of the Study}

Facebook remains the most popular social media site (Duggan, Greenwood, \& Perrin, 2016). Duggan, Greenwood, \& Perrin (2016) found that nearly 8 out of every 10 American users in 2016 engaged with Facebook. What is even more interesting is the majority of Facebook users indicated they obtained their news via a social media site. These same Facebook users stated that they engaged with social media sites during the 2016 presidential elections (Duggan, Greenwood, \& Perrin, 2016). Stringer (2007) suggested that the purpose of analyzing essential experiences was to identify events, which seemed to have made valuable impressions for stakeholder gain.

This study exposed whether trust has a significant role in social media user's engagement and identify what factors determined user trust. The establishment of this trust could be as simple as party affiliation or as complex as bias influence. An underlying question to determine if political bias plays a role in social media response rates to political messages was also explored.

\section{Research Design}

The design of this study was based on the proposed steps by (Hahn, Scherer, Basso, \& dos Santos, 2016), which used cross-sectional survey methods. The data collection was divided into two parts. The first part was the collection of descriptive characteristics of the respondents such as age, gender, race, academic degree, political party affiliation, and the frequency of Facebook and Twitter use. The second part was more exploratory presenting scales that will evaluate trust, negative and positive interpretations of political messages. A Likert scale was used, where respondents completed the scales in degrees of agreement from 1 (strongly disagree) to 5 (strongly agree) (Hahn, Scherer, Basso, \& dos Santos, 2016). Before survey collection began, an application to the Institutional Review Board (IRB) was submitted and approved. Explanation of consent approval and a link was provided to social media recipients through postings on Facebook and Twitter. Recipients agreed that when clicking on the posting link, that they met and consented to the parameters of collection and taking the survey.

\section{RESULTS}

\section{Discussion}

The study's targeted population $(\mathrm{N}=80)$ comprised 30 males and 50 females. A further breakdown of participant demographics included: 37 Baby Boomers, 24 Generation Xers, 14 Millennials, 3 Traditionalists, and 2 Centennials. In an attempt to address the research question, "what motivates social media users to engage with political messages posted within a social media environment such as Facebook or Twitter? " Findings, as shown in Figure $1 \mathrm{a}$ and $1 \mathrm{~b}$, indicated that $62 \%$ of survey respondents engaged in social media daily. Political affiliations ranged from Democratic 43\% (35), Republican 27\% (22), Independent 18\% (15), Libertarian 1\% (1), Green 1\% (1), and designated as other 7\% (6). 
FIGURE 1A

FREQUENCY OF SOCIAL MEDIA ENGAGEMENT

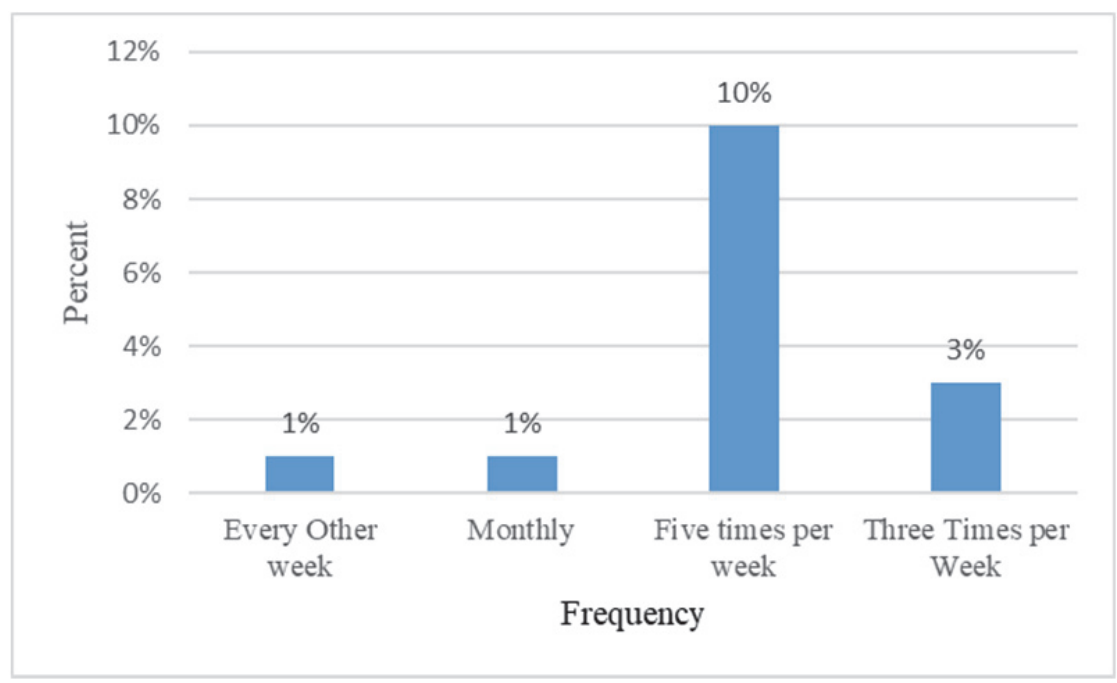

FIGURE 1B

FREQUENCY OF SOCIAL MEDIA ENGAGEMENT

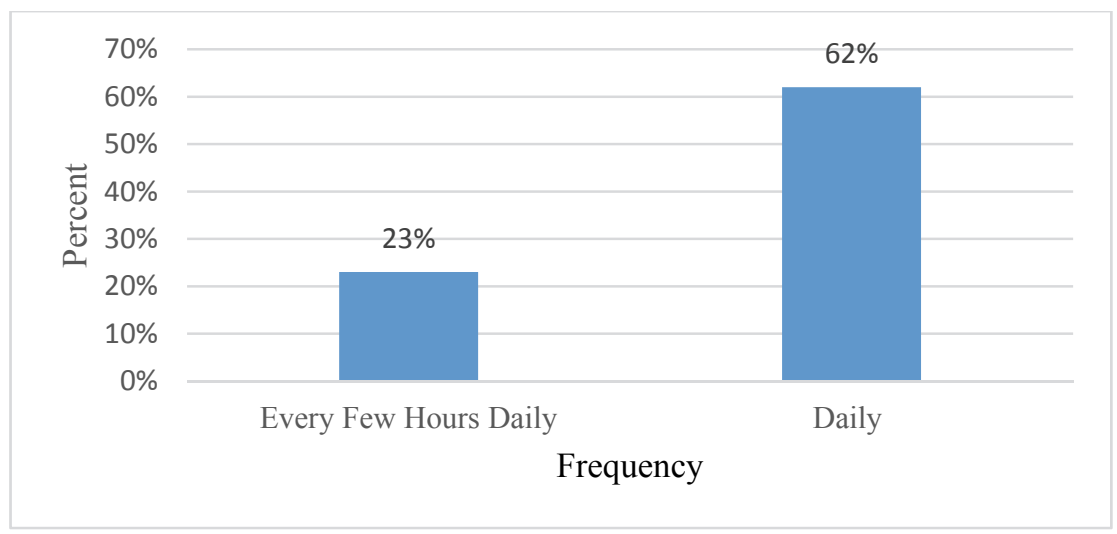

The level of awareness that Facebook and Twitter engaged in providing political messages was affirmed by $96 \%$ (77) of survey respondents with only $3 \%$ (3) of the survey population indicating no knowledge of the practice (Figure 2). 
FIGURE 2

AWARENESS OF POLITICAL MESSAGING BY TWITTER AND FACEBOOK

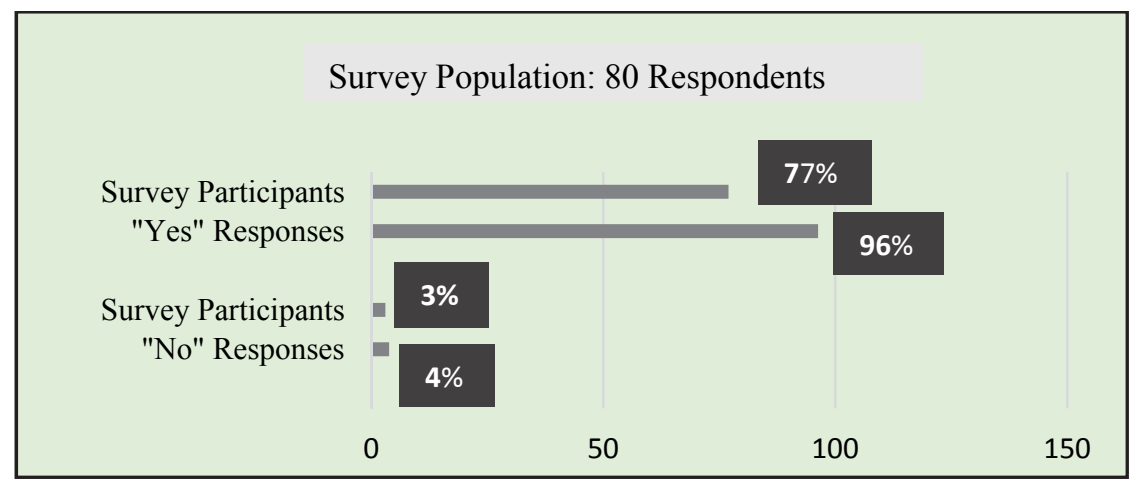

Respondents had a 33\% (27) neutral response when indicating if they were more likely to post on social media if a political message was positive. However, two sub-groups that included those who agreed $28 \%$ (23) they would post a comment and those who strongly agreed $20 \%$ (16) they would post a comment positively overshadowed the results. Whether respondents would engage in social media if political messages were negative garnered a $40 \%$ (32) neutral response rate, a $17 \%$ (14) disagreed response rate and a 26\% (21) strongly disagreed response rate. These results indicated that respondents were not prone to responding to political messaging that did not contribute to the constructive discourse. Survey results indicated that $35 \%$ (28) of respondents had a neutral response to whether they were more likely to respond on social media to a political message from their respective political party.

On the other hand, the response rate for agreement was $23 \%$ (19) and $18 \%$ (15) for strongly agreed, confirmed the likelihood that a significant percentage of respondents are aligned to the political messages originated by their party. In responding to the question, when responding to political messages on Facebook and Twitter, does trust comes into play; respondents agreed at the rate of 40\% (32) and strongly agreed at the rate of $20 \%$ (16) that trust was a key consideration when engaging political messages on social media (Figure 3).

\section{FIGURE 3 \\ TRUST A KEY CONSIDERATION WHEN ENGAGING SOCIAL MEDIA}

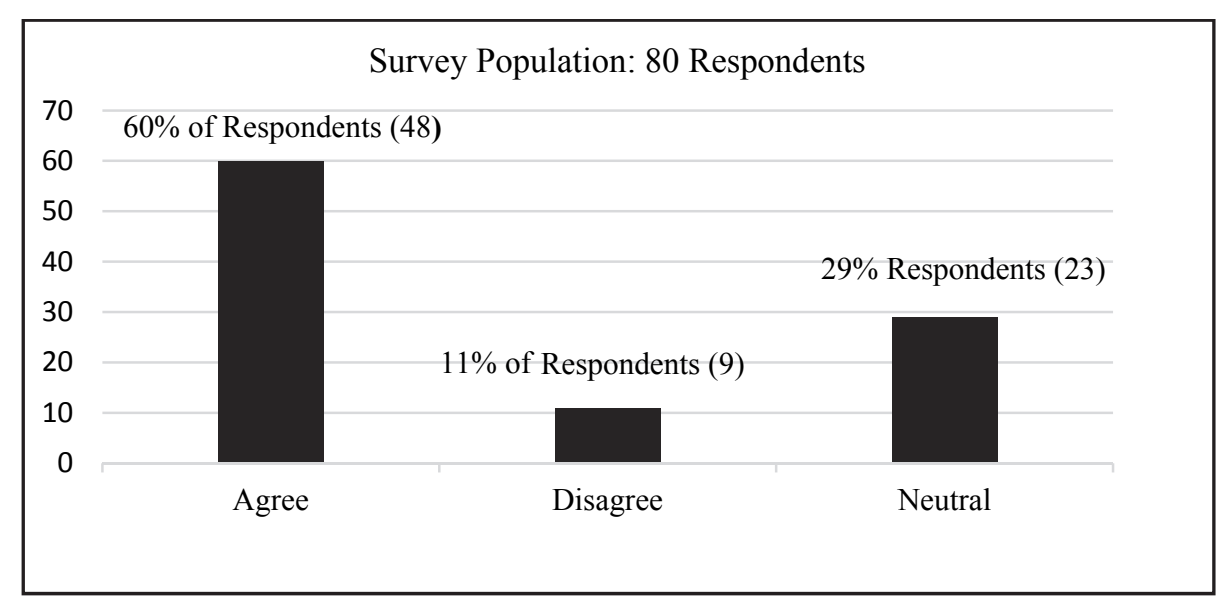

However, there was a $29 \%$ (23) neutral response rate to the question. Respondents rated whether they approved of politicians using Facebook and Twitter to communicate with the public. A 21\% (17) disagreement rate and a $25 \%$ (20) strongly disagree which indicated displeasure with use of social media 
to engage constituents. The question also received a close rating of agreement $33 \%$ (27) and strongly agree $10 \%$ (3) resulting in the conclusion that there is growing acceptance of social media to keep a political base energized and cultivate new supporters. Respondents were closely aligned with their disagreement $32 \%$ (26) to respond to social media political messages if they did not trust the information source and 31\% (25) who would respond. Survey participants agreed 20\% (16) and strongly agreed 3\% (3) that engagement with political candidates or party posts and interactions create trust. In further response to this question, respondents indicated 17\% (14) disagreed and 7\% (6) strongly disagreed. There appeared to be an even split among respondents regarding the trust of political message sources and whether the use of social media to disseminate political messages created trust. Finally, respondents were asked whether a negative post on Facebook or Twitter disrupts the trust with their respective political party. Responses indicated that 37\% (30) of respondents agreed that social media negative political message posting had disrupted the trust in party affiliation and 31\% (25) had a neutral response (Table 1).

TABLE 1

\section{NEGATIVE POLITICAL MESSAGING DISRUPTS TRUST}

\begin{tabular}{|c|c|c|}
\hline $\begin{array}{l}\text { Does negative } \\
\text { political } \\
\text { messages } \\
\text { disrupt trust? }\end{array}$ & \# Of Respondents & Percentage \\
\hline Agree & 33 & $41 \%$ \\
\hline Disagree & 22 & $28 \%$ \\
\hline Neutral & 25 & $31 \%$ \\
\hline
\end{tabular}

\section{Recommendation}

Facebook and Twitter should make a conscious effort to poll users to determine a willingness to reveal political affiliation. Once foundational data has been accumulated, the social media platforms should establish categories for the potential distribution of political messaging. Categories should be designed to appeal to the user. Political messaging should then be provided or not provided to the user based on prior consent.

\section{CONCLUSION}

The use of social media and trust, regarding receipt of political messages, is a complicated issue, and this study narrowly focused on the factors involving social media and trust. However, this study does reveal that social media users are paying attention and do see political messages, which are being posted on social media. Findings also demonstrated that trust does play a critical role in user engagement with these political messages. Lastly, negativity does impede the development of trust among party affiliation demonstrating that when negativity is present, this will unlikely promote engagement. Future research is needed, which looks more deeply into the social media environment and how trust is earned and maintained within a variety of political environments would add tremendous value to the existing body of knowledge. The intense exploration that is required will have the added benefit of preparing society for a closer relationship between social media, politicians, and the user. 


\section{REFERENCES}

Ardèvol-Abreu, A., Diehl, T., Zúñiga, H. (2017). Antecedents of internal political efficacy: incidental news exposure online and the role of political discussion. Politics. Epub ahead of print 10 May. DOI: $10.1177 / 0263395717693251$.

Anderson, M. (2015, August 28). Men catch up with women on overall social media use. Retrieved from http://www.pewresearch.org/fact-tank/2015/08/28/men-catch-up-with-women-on-overall-socialmedia-use.

Bhattacharya, S., \& Soc Choice Welf (2016). 47, 697. https://doi.org/10.1007/s00355-016-0988-6.

Bode, L. (2017). Closing the gender parity in political engagement on social media. Information, Communication \& Society, 20(4), 587-603.

Brader, T. (2006). Campaigns for Hearts and Minds. How Emotional Appeals in Political Ads Work. Chicago, The University of Chicago Press, 280 pp., ISBN 0-226-06989-3.

Brems, C., Temmerman, M., Graham, T., \& Broersma, M. (2017). Personal branding on Twitter. Digital Journalism, 5(4), 443-459.

Chan, M. (2017). Media use and the social identity model of collective action: Examining the role online alternative news and social media news. Journalism and Mass Communication Quarterly, 94(3), 663-681.

Chen, A., Lu, Y., \& Wang, B. (2017). Customers' purchase decision-making process in social commerce: A social learning perspective. International Journal of Information Management, 37(6), 627-638.

Cho, J., Shah, D. V., McLeod, J. M., McLeod, D. M., Scholl, R. M., \& Gotlieb, M. R. (2009). Campaigns, reflection, and deliberation: Advancing an O-S-R-O-R model of communication effects. Communication Theory, 19, 66-88. doi:10.1111/j.1468-2885.2008.01333.

Conroy, M., Feezell, J. T., \& Guerrero, M. (2012). Facebook and political engagement: A study of online political group membership and offline engaement. Computers in Human Behavior, 28, $1535-$ 1546. doi:10.1016/j.chb.2012.03.012.

Correa, T., Hinsley, A. W., \& Gil de Zúñiga, H. (2010). Who interacts on the Web?: The intersection of users' personality and social media use. Computers in Human Behavior, 26, 247-253. doi:10.1016/j.chb.2009.09.003.

Crawford, K. (2009). Following Your: Disciplines of Listening in Social Media. Continuum, 23(4), 525535.

Copeland, L., \& Rommele, A. (2014). Beyond the Base? Political Parties, Citizen Activists, and Digital Media Use in the 2009 German Federal Campaign. Journal of Information Technology and Politics., 11, 169-185.

Duffy, B., Pruchniewska, U., \& Scolere, L. (2017). Platform-specific self-branding: Imagined affordances of the social media ecology. Proceedings of the 2017 International Conference on Social Media \& Society. New York, NY: ACM.

Duggan, M., Greenwood, S., \& Perrin, A. (2016, November 11). Social Media Update 2016: Facebook usage and engagement is on the rise, while adoption of other platforms holds steady. Retrieved from http://www.pewinternet.org/2016/11/11/social-media-update-2016.

Fietkiewicz, K. J., Lin, E., Baran, K. S., \& Stock, W. G. (2016). Inter-generational comparison of social media use: Investigating the online behavior of different generational cohorts. Proceedings of the $49^{\text {th }}$ Hawaii International Conference on System Sciences, 3829-3838. Washington, DC: IEEE Computer Society.

Foa, R.S., \& Mounk, Y. (2016). The democratic disconnect. Journal of Democracy, 27(3), 5-17.

Fridkin, K. L., Courey, J., Hernandez, S., \& Spear, J. (2016) Gender differences in reactions to fact checking negative commercials. Politics \& Gender, 12(2), 369-390.

Fromm, J., \& Porter, K. (2016, June 22). New study finds social media shapes millennial political involvement and engagement. Forbes. Retrieved from https://www.forbes.com/sites/jefffromm/2016/06/22/new-study-finds-social-media-shapesmillennial-political-involvement-and-engagement/\#b6cf9c726189. 
Gerodimos, R., \& Justinussen, J. (2015). Obama's 2012 Facebook campaign: political communication in the age of the Like button. Journal of Information Technology \& Politics, 12, 113-132.

Grimmer, J., Messing, S., \& Westwood, S. (2012). How words and money cultivate a personal vote: the effect of legislator credit claiming on constituent credit allocation. American Political Science Review., 106(4), 703-719.

Ha, Y. H. (2004). Factors influencing consumer perceptions of brand trust online. The Journal of Product and Brand Management, 13(4/5), 329-342.

Hahn, I. S., Scherer, F. L., Basso, K., \& dos Santos, M. B. (2016). Consumer Trust and Emotional Response to Advertisements on Social Media and their Influence on Brand Evaluation. Brazilian Business Review, 13(4), 49-71.

Hajli, N., Sims, J., Zadeh, A.H., \& Richard, M.O. (2017). A social commerce investigation of the role of trust in a social networking site on purchase intentions. Journal of Business Research, 71, 133141.

Henderson, J. A., \& Theodoridis, A. (2015). Seeing spots: An experimental examination of voter appetite for partisan and negative campaign ads. Retrieved from http://dx.doi.org/10.2139/ssrn.2629915.

Hillygus, D., \& Shields, T. (2009). The Persuadable Voter: Wedge Issues in Presidential Campaigns. ( $8^{\text {th }}$ ed.). Princeton University Press.

Himelboim, I., Lariscy, R. W., Tinkham, S. F., \& Sweetser, K. D. (2012). Social media and online political communication: The role of interpersonal informational trust and openess. Jouranl of Broadcasting \& Electronic Media, 56(1), 92-115. doi:10.1080/08838151.2011.648682.

Leung, L. (2013). Generational differences in content generation in social media: The roles of the gratifications sought and of narcissism. Computers in Human Behavior, 29(3), 997-1006. doi:10.1016/j.chb.2012.12.028.

Levy, D. A., Newman, N., Nielsen, R. K., \& Fletcher, R. (2016). Reuters Institute Digital News Report 2016. Reuters Institute for the Study of Journalism.

Mander, J. (2015). Daily time spent on social networks rises to 1.72 hours. Globalwebindex. Retrieved from www.globalwebindex.net/blog/daily-time-spent-onsocial-networks-rises-to-1-72-hours.

McNair, B. (2018). An introduction to political communication. New York, NY: Routledge.

Melewar, T. C., Foroudi, P., Gupta, S., Kitchen, P. J., \& Foroudi, M. M. (2017). Integrating identity, strategy, and communications for trust, loyalty, and commitment. European Journal of Marketing, 51(1), 572-604.

Mitchell, A., \& Weisel, R. (2014). Political Polarization \& Media Habits. From Fox News to Facebook, How Liberals and Conservatives Keep Up with Politics. Pew Research Center.

Muscanell, N., \& Guadagno, R. (2012). Make new friends or keep the old: Gender and personality difference in social networking use. Computers in Human Behavior, 28(1), 107-112. doi:10.1016/j.chb.2011.08.016.

Neubaum, G., \& Krämer, N.C. (2017). Opinion climates in social media: Blending mass and interpersonal communication. Human Communication Research, 43.

Park, C. (2017). Do social media facilitate political learning? Social media use for news, reasoning and political knowledge. The Journal of Social Media in Society, 6(2), 206-238.

Phillips, A. (2017). Beyond 'post-truth': confronting the new reality. Open Democracy. London.

Potgieter, L.M., \& Naidoo, R. (2017). Factors explaining user loyalty in a social media-based brand community. South African Journal of Information Management, 19(1), 744.

Rainie, L., Smith, A., \& Schlozman, K. L. (2012, October 19). Social media and political engagement. Retrieved from Pew Internet: http://pewinternet.org/reports/2012/Political-Engagement.aspx.

Roy, J., \& Alcantara, C. (2016). Fighting fire with fire: The implications of (not) going negative in a multiparty election campaign. Canadian Journal of Political Science, 49(3), 473-497.

Sakakibara, R., \& Endo, T. (2016). Cognitive appraisal as a predictor of cognitive emotion regulation choice. Japan Psychological Research, 58(1), 175-185.

Schill, D., \& Hendricks, J. A. (2018). The Presidency and Social Media: Discourse, disruption, and digital democracy in the 2016 presidential election. London, England: Routledge.

112 Journal of Management Policy and Practice Vol. 20(2) 2019 
Shafiulla, B. (2017). Focus. IUP Journal of Marketing Management, 16(1), 5-6.

Sheth, J. (2017). Revitalizing relationship marketing. Journal of Service Marketing, 31(1), 6-10.

Singhal, T. K. (2016). Impacts of Social Media Expression on Engagement and Trust of Customers. AMITY Business Review, 17(2), 96-103.

Song, C., \& Lee, J. (2015). Citizens' use of social media in government, perceived, transparency, and trust in government. Public Performance and Management Review, 39, 430-453.

Spierings, N., \& Jacobs, K. (2013). Getting Personal? The Impact of Social Media on Preferential Voting. Springer Science + Business Media, 36, 215-234.

Stephen, A. T., \& Toubia, O. (2010, April). Deriving Value from Social Commerce Networks. Journal of Marketing Research, 47, 215-228.

Stevens, D., Sullivan, J., Allen, B., \& Alger, D. (April, 2008). What's Good for the Goose is Bad for the Gander: Negative Political Advertising, Partisanship, and Turnout. The Journal of Politics, 70(2), 527-541.

Stringer, E. T. (2007). Action Research. Thousand Oaks, CA: Sage Publication.

Tanase, T. (2015). The electoral campaign through social media. Sfera Political, 1(183), 92-104.

Twitter and social networking in the 2010 midterm elections. (2011). Retrieved from Pew Internet \& American Life Project: http://pewresearch.org/pubs/1871/internet-politics-facebook-twitter-2010midterm-elections-campaign.

Yichuan, W., \& Chiahui, Y. (2017). Social interaction-based consumer decision-making model in social commerce: The role of word of mouth and observational learning. International Journal of Information Management, 37(3), 179-189.

Van Aelst, P., van Erkel, P., D'heer, E., \& Harder, R. A. (2017). Who is leading the campaign charts? Comparing individual popularity on old and new media. Information Communication \& Society, 20(5), 715-732.

Vraga, E. (2016). Party differences in political content on social media. Online Information Review, 40(5), 595-609.

Warren, A. M., Sulaiman, A., \& Jaafar, N. I. (2014). Facebook: The enabler of online civic engagement for activists. Computers in Human Behavior, 32, 284-289. doi:10.1016/j.chb.2013.12.017.

Weeks, B. E., Ardèvol-Abreu, A., \& Gil de Zúñiga, H. (2017). Online influence? Social media use, opinion leadership and political persuasion. International Journal of Public Opinion Research, 29(2), 214-239.

Wells, C., Shah, D.V., Pevehouse, J.C., Yang, J., Pelled, A., Boehm, F., Lukito, J., Ghosh, S., \& Schmidt, J.L. (2016). How Trump drove coverage to the nomination: Hybrid media campaigning. Political Communication, 33, 669-676.

Young, J. A. (2017). Facebook, twitter, and blogs: The adoption and utilization of social media in nonprofit human service organizations. Human Service Organizations: Management, Leadership \& Governance, 41(1), 44-57. 